\title{
El Libro de Horas del infante don Alfonso en el contexto de la iluminación tardogótica de la Península Ibérica* $^{*}$
}

\author{
Fernando VILLASEÑOR SEBASTIÁN \\ (Universidad de Cantabria)
}

\section{Resumen}

El Libro de Horas del infante Alfonso (New York, Pierpont Morgan Library, M. 854) se ha relacionado tradicionalmente con Alfonso de Castilla (14531468), hermano de Enrique (r. 1454-1474) e Isabel (r. 1474-1504). El posible patronazgo de Alfonso ha sido sugerido tanto por los escudos que aparecen al pie de los folios $15 \mathrm{v}$ y $34 \mathrm{v}$, que corresponden a las armas de la casa real de Castilla, como por la posible representación del joven en dos miniaturas del manuscrito. El ejemplar muestra además una característica orla que bordea todas sus páginas presentando una tipología dominada por el empleo casi exclusivo del gris azulado con pequeñas matizaciones doradas, con una interesante decoración marginal. Uno de los aspectos más singulares son las concomitancias que presenta con otra serie de libros con los que es posible relacionarlo, producto de un taller unitario que habría que insertar en el contexto de la iluminación tardogótica desarrollada en Castilla durante la segunda mitad del siglo XV.

Palabras clave: Infante Alfonso; Enrique IV; Isabel; Morgan Library; Libro de Horas.

* Esta investigación se enmarca dentro del proyecto del Plan Nacional I+D $+\mathrm{i}$ "Arquitectura Tardogótica en la Corona de Castilla: Trayectorias e Intercambios" (ref. HAR2011-25138). 


\section{The Infant Don Alfonso's Book of Hours in the context of the Late Gothic illumination in the Iberian Peninsula}

Abstract

The Book of Hours of the infant Alfonso (New York, Pierpont Morgan Library, M. 854) has traditionally been associated with Alfonso of Castile (1453-1468), brother of Henry (r. 1454-1474) and Elizabeth (r. 1474 - 1504). The possible patronage of Alfonso has been suggested both the shields on the foot of the pages $15 \mathrm{v}$ and $34 \mathrm{v}$, corresponding to the arms of the royal house of Castile, and a possible representation of the young in two miniatures of the manuscript. The sample also shows a border in each page presenting a typology dominated by the exclusive use of the color with small golden details, and an interesting marginal decoration. One of the most unique aspects is the concomitants with another series of books. All of them could be the product of a unit workshop that should be inserted in the context of the Late Gothic illumination developed in Castile during the second half of the fifteenth century.

Key words: Infant Alfonso; Henry IV; Elizabeth; Morgan Library; Book of Hours.

El infante Alfonso de Castilla (1453-1468), hijo menor de Juan II e Isabel de Portugal, hermanastro de Enrique IV de Castilla (r. 1454-1474), hermano de Isabel I (r. 1474-1504), y último Trastámara castellano; fue destinado a reinar en Castilla de forma paralela junto con su hermano Enrique entre $1465 \mathrm{y}$ 1468, año en el fallecía prematuramente en Cardeñosa, posiblemente envenenado, en pleno conflicto sucesorio. ${ }^{1}$

\footnotetext{
${ }^{1}$ Sobre el personaje, es obligado citar la clásica obra de Juan TORRES FONTES, El príncipe don Alfonso y su itinerario: la contratación de Guisando, Murcia, Departamento de Historia Medieval de la Universidad de Murcia, 1985, pero, sobre todo, los trabajos de $\mathrm{M}^{\mathrm{a}}$ del Carmen Morales MuÑIZ: «Alfonso XII de Trastámara y el Principado de Asturias, 14651468», Universidad y Sociedad, 5 (1982), pp. 261-72; «El primer Alfonso XII y Palencia», en Actas del I Congreso de Historia de Palencia, Palencia, 1987, vol. II, pp. 527-37; «La política de mercedes del rey Alfonso XII de Castilla: el sostenimiento de su causa», en Homenaje al Profesor Juan Torres Fontes, Murcia, Universidad de Murcia, 1987, vol. II, pp. 1125-39; Alfonso de Avila, rey de Castilla, Ávila, Institución Gran Duque de Alba, 1988; «Las mercedes del rey Alfonso XII a la villa de Arévalo», Anuario de Estudios Medievales, 16 (1988), pp. 481-3; «Documentación acerca de la administración de la Orden de Santiago por el príncipe-rey Alfonso de Castilla», Hidalguía, 211 (1988), pp. 839-68; «Andalucía ante la crisis de 1464: los años de Alfonso XII», Archivo Hispalense, 216 (1988), pp. 3-35; «Alfonso ¿Príncipe de
} 
Entre los numerosos libros de Horas conservados en la Pierpont Morgan Library de Nueva York, uno de ellos (M. 854) ha sido tradicionalmente relacionado con el infante. ${ }^{2}$ La vinculación con Alfonso se ha podido deducir, tanto por la posible presencia de la efigie del infante en el folio 15v (fig. 1), así como por los detalles heráldicos del mismo, ${ }^{3}$ al corresponder las armas que aparecen al pie de los folios $15 \mathrm{v}$ y 34v (fig. 2) con las de la casa real de Castilla - en campo de gules, castillo de oro almenado y donjonado de tres torres cada una con tres almenas-. ${ }^{4}$

Asturias?», en Actas del Congreso sobre los Orígenes de la Junta y el Principado de Asturias, Oviedo, 1988; «Las confederaciones nobiliarias de Castilla durante la guerra civil de 1465», Anuario de Estudios Medievales, 18 (1988), pp. 455-67; Contribución al registro diplomático del rey Alfonso XII de Castilla: La documentación de Avila, Madrid, EU Santa María, 1991; «Contribución al estudio de la nobleza extremeña durante el reinado de Alfonso XII de Castilla», Revista de Estudios Extremeños III, Tomo XXXLV (1989), pp. 505-28; «Significación e historiografía de Alfonso XII de Castilla: nuevas vías de investigación», Medievalismo: Boletín de la Sociedad Española de Estudios Medievales, 6 (1996), pp. 213-37.

2 Cfr. Meta HARrSEN, «Mediaeval and Renaissance Miniatures in the John Frederick Lewis Collection in Philadelphia», Scriptorium, XIV/1 (1960), pp. 75-9 (p. 76); Lynette, M.F. Bosch, Manuscript Illumination in Toledo (1446-1495): The Liturgical Books, Ph.D. thesis, Princeton University, 1985, pp. 536-42; Wilma FitzGERALD, Ocelli Nominum: Names and Shelf Marks of Famous/Familiar Manuscripts, Toronto, 1992, 10b; Dr. Jörn GÜNTHER ANTIQUARIAT, Mittelalterliche Handschriften und Miniaturen: Katalog und Retrospektive, Hamburg, 1993, p. 150; Judith Berg Sobré and Lynette M. F. BosCH, The Artistic Splendor of the Spanish Kingdoms: The Art of Fifteenth-Century Spain, Boston, 1996, pp. 56-60, no 14, fig. 14; Roger S. WIECK, Painted Prayers: The Book of Hours in Medieval and Renaissance Art, New York, 1997, p. 71, $\mathrm{n}^{\circ}$ 51; Lynette M.F. BosCH, Art, Liturgy, and Legend in Renaissance Toledo. The Mendoza and the Iglesia Primada, The Pennsylvania State University Press, 2000, pp. 98-103; pl. III, figs. 26, 31; James FrANCE, Medieval Images of Saint Bernard of Clairvaux, Kalamazoo, 2007, fig. MA310; Colum HouriHane (ed.), Time in the Medieval World: Occupations of the Months \& Signs of the Zodiac in the Index of Christian Art, Princeton, 2007, pp. 1, 10, 23, fig. 2, pl. 616; Fernando VILLASEÑOR SEBASTIÁN, El libro iluminado en Castilla durante la segunda mitad del siglo XV, Burgos, Instituto Castellano y Leonés de la Lengua, 2009, pp. 36, 38, 49, 103, 129-33, 346, no 216, figs. 64-83; María Jesús LóPEz MontiLLA, El Libro de Horas: Un libro selecto de devoción privada, Madrid, 2012, p. 64, fig. 2; Lieve de KESEL, The Hours of Queen Isabella the Catholic: The Cleveland Museum of Art, Cleveland/Ohio, Leonard C. Hanna Jr. Fund 1963.256, Gütersloh, 2013, pp. 98, 207.

${ }^{3}$ BosCH, Art, Liturgy..., p.103, notas 155 y 156.

${ }^{4}$ Véase Faustino MenÉndeZ PIDAL, Heráldica de la Casa Real de León y de Castilla (siglos XIIXVI), Madrid, Ediciones Hidalguía, 2011. 


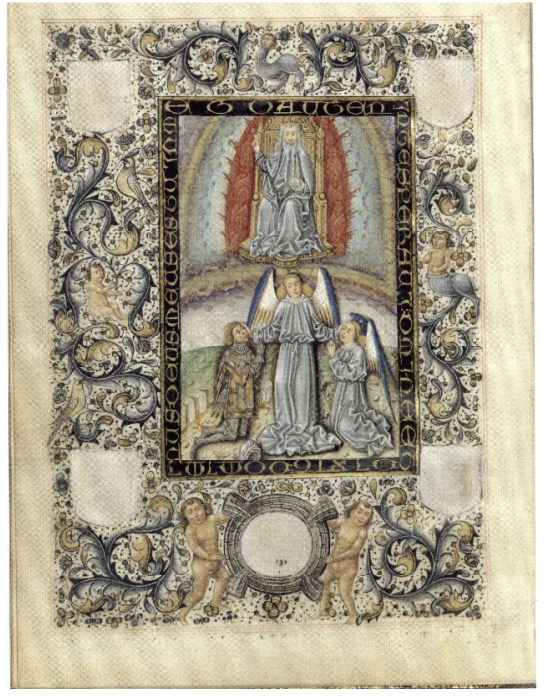

Fig. 1. Libro de Horas del infante Alfonso (New York, Pierpont Morgan Library, M. 854, fol. 15v)

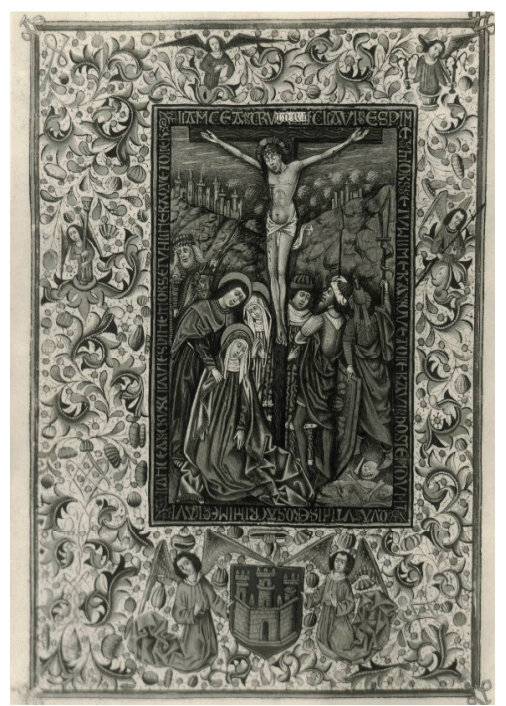

Fig. 2. Libro de Horas del infante Alfonso (New York, Pierpont Morgan Library, M. 854, fol. 34v)

Morales Muñiz consideró que dichas armas eran las del infante e insistió en ver un retrato del mismo en la miniatura del folio $15 \mathrm{v}$, donde aparece, a la izquierda, un joven arrodillado y ataviado con cota de malla -en cuyos extremos se representan igualmente leones y castillos- junto a un ángel a la derecha que mantiene la misma posición. Según la autora, la armadura, los pliegues de la prenda, la pose, las facciones y la presencia de los ángeles es similar a la representación iconográfica que Gil Siloé desarrolló años más tarde en la efigie funeraria de su tumba en la Cartuja de Miraflores. ${ }^{5}$ Ampliamente sugerente resulta el hecho de que la iconografía alfonsí esté íntimamente relacionada con las figuras de ángeles; partiendo del propio Alonso de Palencia que lo definía como "un dechado de angelicales virtudes". ${ }^{6}$

${ }^{5}$ BOSCH, Art, Liturgy..., p. 103, notas 155 y 156. Sobre el escultor, cfr. August L., MAYER, «El escultor Gil de Siloe», Boletín de la Sociedad Española de Excursiones, XXXI (1923), pp. 2526; Harold Wethey, Gil de Siloe and his School, Cambridge, Mass, 1936; Juan de SALAZAR, «El origen flamenco de Gil Siloe», Archivo Español de Arte, XIX (1946), pp. 228-42; Beatrice Proske, Castilian Sculpture, Gothic to Renaissance, New York, The Hispanic Society, 1951. Las aportaciones más recientes de Joaquín YARZA LuACES, Gil de Siloe, Cuadernos de Arte Español, $\mathrm{n}^{\circ}$ 3, Madrid, Historia 16, 1991; idem, «El Retablo Mayor de la Cartuja de Miraflores», Actas del Congreso Internacional sobre Gil Siloe y la escultura de su época, Burgos, 2001, pp. 207-38. Un estudio específico sobre el sepulcro del infante Alfonso, en $\mathrm{M}^{\mathrm{a}}$ Dolores TEIJIEIRA PABLOS, «Un ejemplo de iconografía marginal funeraria: la orla del sepulcro del infante Alfonso en la Cartuja de Miraflores», Reales Sitios, 133 (1997), pp. 36-43.

${ }^{6}$ Morales MuÑIZ, «Significación e historiografía...», p. 215. 
A esto habría de añadirse el juicio de Domínguez Rodríguez respecto al hueco en blanco de las cuatro esquinas del 15v, al señalar como en el escudo superior izquierdo se aprecia, al ser examinado por el verso del folio, que era acuartelado y que en el cuarto cuartel había un león. ${ }^{7}$

No debe extrañar, además, un encargo de estas características en un personaje vinculado a la casa real castellana; más aún cuando en los tres breves años que duró su reinado, Alfonso tuvo una corte perfectamente estructurada, una sólida administración, una cancillería efervescente, la acuñación de moneda propia y el apoyo hasta su muerte de la casi totalidad del reino. ${ }^{8}$ Además, a pesar de ser un ámbito en el que todavía se debe profundizar, es probable que, don Alfonso, en la línea de soberanos anteriores como su propio padre, se sintiera interesado por las corrientes culturales y fomentara la existencia de una corte alfonsina, ámbito caballeresco en la que estuvieron presentes poetas como Jorge y Gómez Manrique; junto a la potenciación que don Alfonso hizo de la Orden de la Banda, Orden de Caballería por excelencia. ${ }^{9}$ En este contexto debe entenderse el encargo y su vinculación al personaje, configurándose con una de las mejores obras de la iluminación castellana del tercer cuarto del siglo XV.

Sin embargo, la datación de la obra es problemática porque, mientras que la miniatura del folio $15 \mathrm{v}$ muestra a Alfonso vivo y arrodillado ante el trono de Dios, ${ }^{10}$ existe otra, en el fol. 163v (fig. 3), en la que aparece un joven muerto,

7 Ana Domínguez Rodríguez, «Libros de Horas españoles. Hacia un estado de la cuestión» Anales de Historia del Arte, 10 (2000), p. 38. Sin embargo, las armas que aparecen sostenidas por ángeles en el folio $34 \mathrm{v}$-castillo torreado de oro en campo de gules- fueron empleadas también por la familia Carrillo de Acuña, y esto llevó a Domínguez Bordona a defender que el Libro perteneciese al arzobispo Carrillo de Acuña (Jesús DomínguEz Bordona, Exposición de Códices miniados españoles. Catálogo, Madrid, Sociedad Española de Amigos del Arte, 1929, p. 131). En ese caso, habría que relacionar el manuscrito con el Breviario conservado en París que posee las mismas armas. A pesar de que parece más viable la vinculación del Libro de Horas con el Infante, su relación con el arzobispo no debe ser obviada ya que, éste estuvo en el círculo próximo al infante, intervino en la Farsa de Ávila y, además, en el Breviario de París, existe una dedicación especial en los folios 292295 hacia San Ildefonso.

${ }^{8}$ Morales MuÑIZ, Contribución al registro..., p. 7.

${ }^{9}$ MORAles MuÑIZ, «Significación e historiografía...», p. 227.

${ }^{10}$ Esta miniatura, según Domínguez, se le supone una gran originalidad iconográfica al ir acompañada de una oración excepcional en los Libros de Horas, titulada como oración del domingo y conmemoración al trono del Señor. En la parte superior aparece el Señor entronizado, dentro de una mandorla de querubines, y abajo a un ángel en pie, como eje central, a cuyos lados se arrodillan respectivamente un joven, acariciado por un ángel, y otro ángel. La incripción del borde reza: "Ego Autem/In te Speravi Domine et/Dixit Dominus/Deus Meus Es Tu In". El primero es el arcángel San Miguel mientras que el segundo se trataría del ángel de la guarda, ya que el Libro de Horas de los Zúñiga presenta 
cuya fisonomía es similar a la del fol. $15 \mathrm{v}, 11$ en primer plano junto con un grupo de personajes en los que se ha querido ver a los magnates del reino. ${ }^{12}$ Detrás de la muerte cabalgando se representa una reina rubia cuyas facciones se identifican, según Panofsky, ${ }^{13}$ como las de su hermana Isabel. Si esto es así, la miniatura debería datarse como posterior a la muerte de Alfonso. Este dilema cronológico, directamente relacionado con la datación del manuscrito, Bosch lo resuelve por la posición que en las Horas Morgan se dio a Alfonso antes de su muerte, siendo la obra completada por Isabel algún tiempo después de 1468. Posiblemente, el manuscrito fuera encargado al tiempo que Alfonso era proclamado rey, el 27 de abril de 1465, y debió completarse después de su muerte y la coronación de Isabel en 1474, lo que permite datar las Horas entre 1465-1475/80.14

Lamentablemente no existe referencia sobre su localización primitiva y posible lugar de ejecución ya que, aunque se iluminó enteramente, faltan en el texto del Calendario los nombres de los santos. ${ }^{15}$ En una nota del códice se lee: «Por mandado y comisión de los ilustres señores inquisidores de Valladolid fueron estas horas vistas y examinadas por mi fray Nicolás Ramos». Este personaje (1531-1596) pasó a ser obispo de Puerto Rico en 1588, lo que permite localizar el códice en la ciudad castellana hasta ese momento. La siguiente referencia viene determinada por la encuadernación, en tafilete rojo con las armas de Felipe V. ${ }^{16}$ En febrero de 1894 figuraba en la venta de libros de la colección del conde Lignerolles, ${ }^{17}$ desde 1929 estaba en la del barón Vittá, entrando en 1951 en la Morgan Library. ${ }^{18}$

un ángel con filacteria al que se denomina de este modo y por tanto podría asimilarse al mismo. Domínguez RodrígueZ, «Libros de Horas españoles...», p. 37, nota 96.

11 Dicha miniatura ya fue reproducida, en blanco y negro por Jesús DOMínGUEZ BORDONA, La miniatura española, Florencia y Barcelona, Gustavo Gili, 1930, p. 205, fig. 263, quien comentó también el retrato del donante del fol. $15 \mathrm{v}$.

${ }^{12}$ MORALES MUÑIZ, «Significación e historiografía...», p. 228.

13 Erwin PANOFSKY, Early Netherlandish Painting, Cambridge Mass, Harvard University Press, 1953, p. 349.

${ }^{14}$ BosCH, Art, Liturgy..., p.103.

${ }^{15}$ Domínguez Rodríguez, «Libros de Horas españoles...», p. 38.

${ }^{16}$ Domínguez Bordona, Exposición de Códices miniados españoles. Catálogo, p. 131, nota 1.

${ }^{17}$ R. L. Lignerolles, Catalogue des libres rares et prècieux, París, 1894 y Catalogue des livres $d u$ Comte Lignerolles. 1 Partie vendue a Paris du 29 Janvier au 3 Fevrier 1894.

18 Treasures from the Pierpont Morgan Library, New York, 1957, $\mathrm{n}^{\circ} 36$, pl.30; y Mediaeval and Renaissance Manuscripts: Major Acquisitions of the Pierpont Morgan Library, 1924-1974, New York, 1974, n. 41.

Titivillus, ISSN 2387-0915, ISSN-e 2603-9966, 1 (2015), pp. 89-100 
El manuscrito tiene veinticuatro miniaturas que ocupan el folio completo, ${ }^{19}$ dominadas por los tonos grisáceos, con una preponderancia manifiesta de la grisalla. Ocho pequeñas miniaturas corresponden al Sufragio de los Santos ${ }^{20}$ y el calendario está sin terminar, figurando en él las fechas, pero no los nombres de las festividades, y en la parte inferior los trabajos de los meses y los signos zodiacales. Hay que mencionar como en la bordura superior de la primera página del calendario hay un bello retrato que Domínguez Bordona identificó como el del miniaturista, algo que resulta cuestionable (fig. 4) ${ }^{21}$.

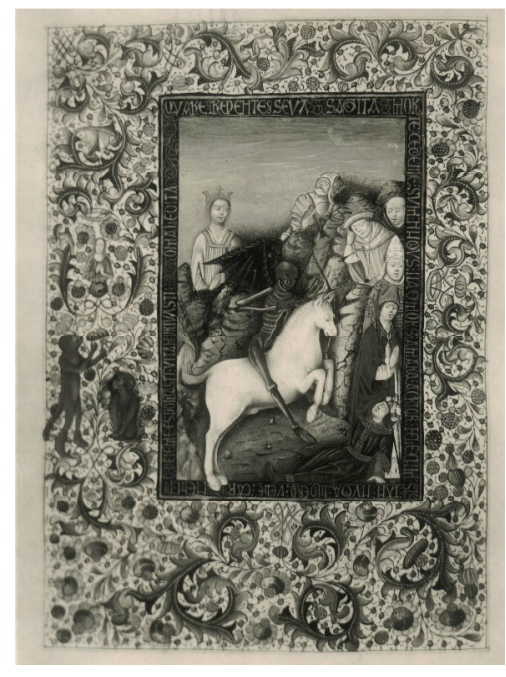

Fig. 3. Libro de Horas del infante Alfonso (New York, Pierpont Morgan Library, M. 854, fol. 163v)

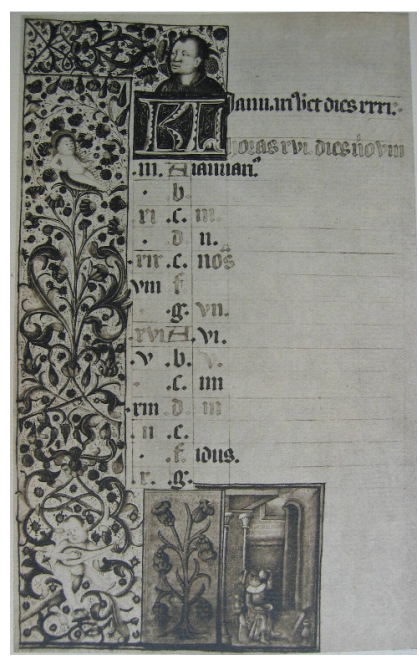

Fig. 4. Libro de Horas del infante Alfonso (New York, Pierpont Morgan Library, M. 854)

\footnotetext{
${ }^{19}$ Miden 130 X $80 \mathrm{~mm}$. y desarrollan la siguiente temática: Verónica (1v), Donante arrodillado (15v), San Juan Bautista (20v), San Juan Evangelista (22v), Crucifixión (34v), Trinidad entronizada (43v), Anunciación (53v), Visitación (62v), Natividad (80v), Anunciación a los pastores (85v), Adoración de los Magos (90v), Presentación (95v), Masacre de los inocentes (100v), Huida a Egipto $(108 \mathrm{v})$, Virgen y niño (122v), Lamentación (129v), Juicio Final (135v), Resurrección de Lázaro (154v), Muerte (163v), San Bernardo del Claraval (199v), Última cena (212v), Pentecostés (209v), San Ildefonso (217v), Misa de San Gregorio (225v).

${ }^{20}$ San Cristóbal (191), Santa Catalina (192), San Miguel (193), San Andrés (194), San Francisco (196), San Sebastián (197) y San Ildefonso (198).

${ }^{21}$ Bordona esgrime que, "aunque no con frecuencia, los miniaturistas dejaron alguna vez su autorretrato en orlas de ricos manuscritos. Tal, por ejemplo, el de Antonio Verard en el Libro de Horas de Carlos VIII de Francia”. Domínguez Bordona, Exposición de Códices miniados españoles. Catálogo, p. 131, nota 2.
} 
Bosch señalaba la intervención del trabajo de cuatro artistas. ${ }^{22}$ El primero, el Maestro del Calendario Morgan, que fue responsable de la iluminación del Calendario y de las miniaturas que acompañan el Sufragio de los Santos; el Maestro Mendoza, responsable de las miniaturas del retrato del donante (fol. 15v), San Juan Evangelista (fol. 22v) y San Juan Bautista (fol. 20v) (fig. 5); el Maestro de la Verónica, designado así por corresponderle esta escena (fol. 1v) y las del Juicio Final (fol.135v), la Muerte (fol.163v), la Última Cena (fol. 202v), Pentecostés (fol. 209v), Todos los santos (fol. 217v) y La Misa de San Gregorio (fol. 225). La última mano quedaría definida por el Maestro de las Horas Morgan, que ejecutó el resto de las miniaturas, entre ellas la de la Crucifixión (fol. 34v).

La problemática de identificación de los autores materiales de las citadas miniaturas, radica en asignar unos rasgos diferenciadores a un conjunto de artistas no documentados que desarrollan unas características semejantes; y su similitud con otras obras ejecutadas en el mismo periodo y en un marco geográfico próximo; muy relacionadas con el confuso círculo de Juan de Carrión. ${ }^{23}$

Pueden rastrearse entonces cierta aproximación entre estas miniaturas, y algunas realizadas en el ejemplar del Libro del caballero Zifar conservado en Paris (Bibliotèque Nationale, Espagnol 36). ${ }^{24}$ Las relaciones aparecen en la escena dedicada al donante postrado ante Dios Padre (fol. 15v), y sobre todo, en el paisaje del fondo, al interpretar los desniveles del terreno bajo un prisma geometrizante similar al que aparece en el Zifar. La miniatura dedicada a San Juan Bautista (fol. 20v) hace gala del mismo fenómeno. Las afinidades también se hacen presentes en el tratamiento escultórico de los pliegues, mediante una gama cromática grisácea y un tipo de expresión facial que acusa los rasgos de tristeza, que se observa, por ejemplo, en la Crucifixión (fol. 34v).

\footnotetext{
${ }^{22}$ BosCH, Manuscript Illumination in Toledo (1446-1495): The Liturgical Books, p. 541.

${ }^{23}$ Sobre éste, v. Lynette, M.F. BosCH, «Los manuscritos abulenses de Juan de Carrión», Archivo Español de Arte, 253 (1991), pp. 55-64; «Iluminación en Ávila y Segovia durante el siglo XV: los libros litúrgicos del grupo de Juan de Carrión», Archivo Español de Arte, 256 (1991), pp. 471-87; «El taller de Juan de Carrión: los libros seculares», Archivo Español de Arte, 264 (1993), pp. 353-71. Una discusión sobre el iluminador y su entorno, vinculándolo al círculo regio del rey Enrique IV en VILLASEÑOR SEBASTIÁN, El libro iluminado en Castilla durante la segunda mitad del siglo XV, pp. 99-138 y aproximación biográfica en p. 303.

${ }^{24}$ VILLASEÑOR SeBAStián, El libro iluminado en Castilla durante la segunda mitad del siglo XV, pp. 117-21.
}

Titivillus, ISSN 2387-0915, ISSN-e 2603-9966, 1 (2015), pp. 89-100 


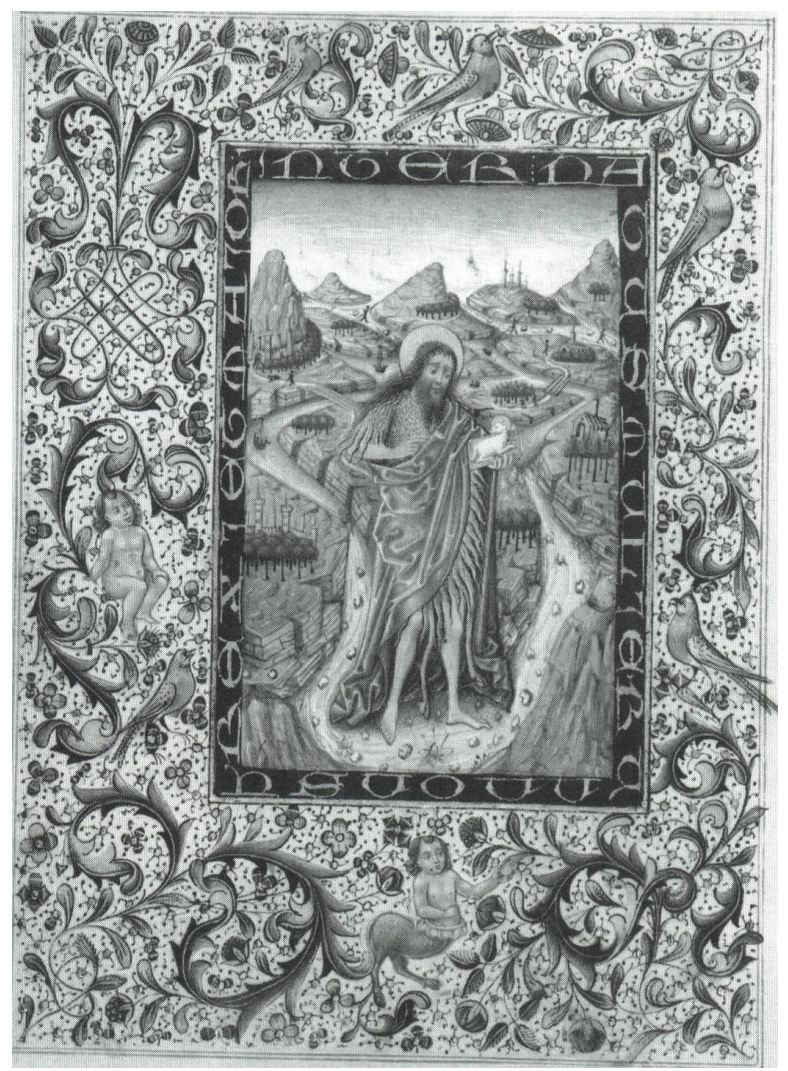

Fig. 5. Libro de Horas del infante Alfonso (New York, Pierpont Morgan Library, M. 854, fol. 20v)

La relación con otras obras vinculadas al taller de Carrión se pone también de manifiesto en aspectos tanto estilísticos como compositivos. En este sentido, el tipo de paisaje que aparece en la escena de San Juan Bautista (fol. 20v) del Manuscrito de la Morgan Library es muy similar al que aparece en la Historia de Roma de Orosio (Cambridge, Fitzwilliam Museum, Mc Clean Collection, ms. 180, ca. 1442), al que sirve de fondo a las miniaturas de la Crucifixión y los Ocho santos conservados en la École des Beaux-Arts de París (Collection Jean Masson, $\mathrm{n}^{\mathrm{o}} 151$ y 152, ca. 1454-1472) (fig. 6); ${ }^{25}$ al de la Virgen sobre el Infierno de un Libro de Horas conservado en la Biblioteca del Real

25 Villaseñor Sebastián, El libro iluminado en Castilla durante la segunda mitad del siglo XV, pp. 137-8. 
Monasterio de El Escorial (Vit. 11, fol. 97v, anterior a 1469);26 al del San Eustaquio del Libro de Horas de la British Library (Add. MS. 50004, fol. 86v, ca. $1450-1474)^{27}$ y al de la Natividad de Juan de Carrión en los Libros de Coro de la catedral de Ávila (1470-1472).

Las piedras dispersas como fragmentos independientes en el camino que recorre San Juan recuerdan a las representadas en el folio 130v del Zifar, relativa al exemplo correspondiente a los Castigos del rey de Mentón donde los súbditos lapidan al monarca de su reino. La cara de San Juan Bautista corresponde bien al tipo de fisonomía desarrollada por Juan de Carrión y su taller, caracterizado por ojos como gotas y pequeñas bocas con el labio inferior enfatizado; y los pliegues drapeados de la túnica de éste encuentran su contrapartida en la ropa que llevan muchas figuras en las miniaturas citadas arriba. Indicios que llevan a suponer que la iluminación de las Horas Morgan encaja perfectamente con el estilo del taller de Juan de Carrión.

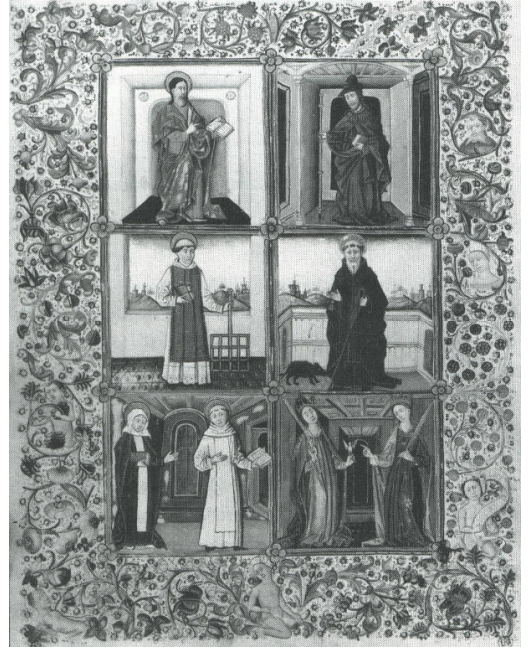

Fig. 6. Ocho santos (Paris, École des Beaux-Arts, Collection Jean Masson, $\left.\mathrm{n}^{\circ} 152\right)$

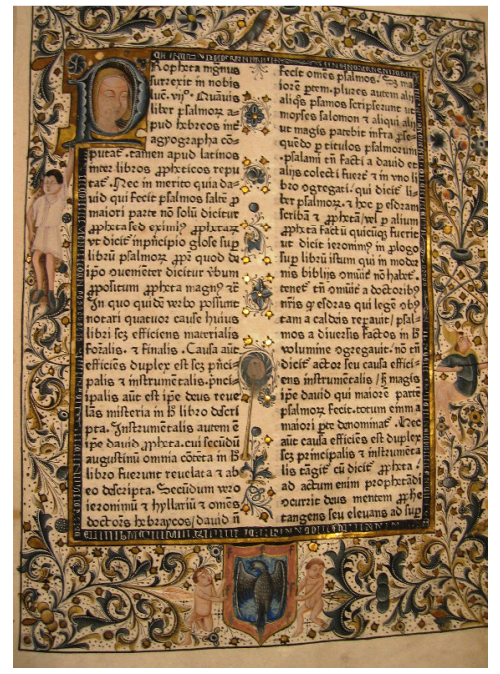

Fig. 7. Nicolas de Lyra, Postilla super Psalterium (Segovia, Archivo de la Catedral)

Sin embargo, el elemento de mayor singularidad de las Horas Morgan, lo constituye el tipo de orla que bordea sus páginas que la alejan de las típicamente carrionescas, y se aproxima a una nueva modalidad que va a tener gran fortuna en el ámbito castellano durante estos años. En éstas, domina el empleo casi exclusivo del gris azulado con pequeñas matizaciones doradas.

26 Villaseñor Sebastián, El libro iluminado en Castilla durante la segunda mitad del siglo XV, pp. 133-4.

27 Villaseñor SeBASTIÁN, El libro iluminado en Castilla durante la segunda mitad del siglo XV, pp. 123-6. 
Los motivos figurativos se han reducido considerablemente en una preferencia clara por el predomino de los putti, solos o como tenantes, pero con un mayor cuidado anatómico y una tendencia hacia modelos más italianizantes, con interesantes matizaciones pictóricas y carnaciones que producen efectos de gran naturalismo en la reproducción de la piel. Los modelos empleados para las caras se repiten a la hora de representar seres fantásticos con patas traseras animales y la fauna se reduce prácticamente a la representación de pájaros o alguna especie dispersa como la pareja de monos de la hoja de la Muerte cabalgando. Especialmente interesante resulta la orla que bordea la página de la Crucifixión donde la figuración marginal se compone exclusivamente de ángeles, bien tenantes sosteniendo el escudo de la Casa Real de Castilla, o los cuatro restantes portando los instrumentos de la Pasión: la columna, las varas -cilicios- de la flagelación, la lanza de la transfixión y un cuarto elemento que llevado por el ángel del margen superior correspondería a alguna de las Arma Christi, pero sin una clara identificación.

El tipo de orla descrito junto al formato empleado al componer las miniaturas que ocupan una página completa - escena principal en el centro del folio rodeada por una inscripción en letras doradas sobre fondo negro orlándola; en la parte baja dos tenantes, ángeles o putti, sostienen el escudo del donante y todo enmarcado por una bordura dominada por la grisaya-, tiene relación con dos incunables localizados en el Archivo de la catedral de Segovia correspondientes a la obra de Nicolas de Lyra, Postilla super Psalterium, ${ }^{28}$ y fechados por una inscripción en 1479 (fig. 7).

Además, la iluminación del Libro de Horas del infante don Alfonso muestra claras concomitancias con otra serie de manuscritos, de procedencia probablemente castellana, con los que debe ser relacionado: la Traducción y glosas de Juan García de Castrogeriz a un Regimiento de principes (Salamanca, Biblioteca de la Universidad, ms. 2709) (fig. 8); la Traducción de las obras de Séneca realizada por Alonso de Cartagena por orden de Juan II (Salamanca, Biblioteca de la Universidad, ms. 201); el Libro de Horas de la reina Leonor de Portugal (Lisboa, Biblioteca Nacional de Portugal). Finalmente, y en clara relación con las obras anteriormente descritas, habría que vincular también una serie de ejemplares relacionados con Juan de Zúñiga y Pimentel, último Maestre de la Orden de Alcántara, ${ }^{29}$ pero de cronología, algo más tardía, en torno a los años 80 y 90 de la decimoquinta centuria: el Libro llamado de los pensamientos variables (Madrid, Biblioteca Nacional, ms. 6642), procedente del convento de los

\footnotetext{
${ }^{28}$ Cristino Valverde Del Barrio, Catálogo de los Incunables y libros raros de la Santa Iglesia Catedral de Segovia, Segovia, Imprenta de «El Adelantado», 1930, núms. 298 y 299, p. 198.

29 Fernando Villaseñor Sebastián, «La corte literaria de Don Juan de Zúñiga y Pimentel (Plasencia, 1459-Guadalupe 1504)», Anales de Historia del Arte 2013, 23, Núm. Especial (II), (2013), pp. 581-94.
} 
dominicos de Plasencia; 30 el Comentario a las Crónicas de Eusebio, de Alfonso de Madrigal (Lisboa, Biblioteca Nacional de Portugal, ca. 1489); la segunda edición de las Introducciones Latinae de Antonio de Nebrija (Madrid, Biblioteca Nacional, Vit. 17-2), ${ }^{31}$ fechable entre 1493-1494 y editada probablemente en Burgos; y una Biblia impresa para el Maestre (Paris, Bibliothèque National, Velin 80, ca. 1480-1494) (fig. 9) ${ }^{32}$.

El gusto por los matices tristes y sombríos, las orlas en negro y oro, negro y gris, o negro y blanco, que caracteriza a todo el conjunto, predispone a realizar un análisis de este grupo de obras como producción de un taller unitario que habría que insertar en el contexto de la iluminación tardogótica desarrollada en Castilla durante la segunda mitad del siglo XV.

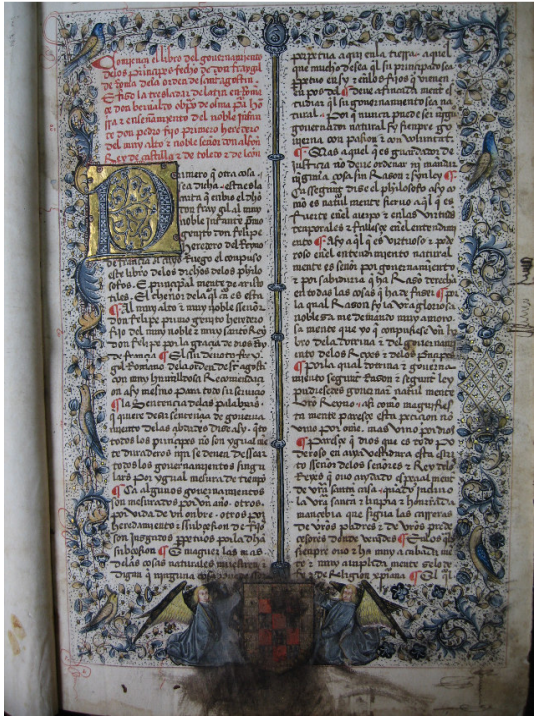

Fig. 8. Traducción y glosas de Juan García de Castrogeriz a un Regimiento de príncipes (Salamanca, Biblioteca de la Universidad, ms. 2709 , fol. $1 \mathrm{r}$ )

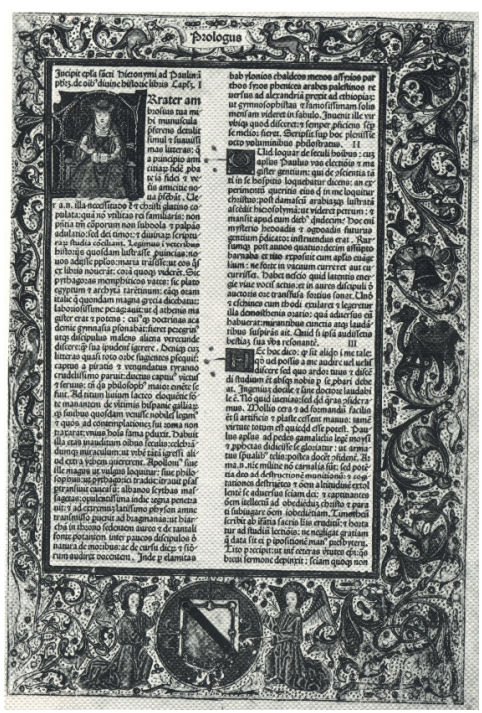

Fig. 9. Biblia impresa (Paris, Bibliothèque National, Velin 80)

\footnotetext{
${ }^{30}$ Villaseñor Sebastián, «La corte literaria de Don Juan de Zúñiga...», p.592, nota 40.

31 E. SÁNCHEZ SALOR, «La segunda edición de las Introductions latinae de Nebrija: el ejemplar de don Juan de Zúñiga», Revista de Estudios Extremeños, 59, 2 (2003); VILLASEÑOR SEBASTIÁN, «La corte literaria de Don Juan de Zúñiga...», pp. 586-8.

${ }^{32}$ Sobre ésta, v. F. AVRIL et alii, Manuscrits enluminés de la Péninsule Ibérique, París, 1982, nº 154, pl. LXXXVIII-XC, pp. 138-41; D. Hillard, «Biblia latina», A. CORON (dir.), Des Livres rares depuis l'invención de l'imprimerie, Paris, 1998, ficha 15, p. 35. Discusión sobre la misma en relación al resto de obras vinculadas a Juan de Zúñiga y Pimentel en VILLASEÑOR SEBASTIÁN, «La corte literaria de Don Juan de Zúñiga...», pp. 588-91.
} 